\title{
1 Extreme drought triggers transition to an alternative soil microbial state
}

2 Irene Cordero ${ }^{1, *}$, Ainara Leizeaga ${ }^{2}$, Lettice C. Hicks ${ }^{2}$, Johannes Rousk ${ }^{2}$ and Richard D.

3 Bardgett $^{1}$

$4{ }^{1}$ Department of Earth and Environmental Sciences, The University of Manchester,

5 Michael Smith Building, Oxford Road, Manchester, M13 9PT, UK

$6 \quad{ }^{2}$ Department of Biology, Lund University, Sweden.

$7 \quad$ * Corresponding author: Irene Cordero

8 Tel.: +44 16130 68074; e-mail: $\underline{\text { irene.cordero@manchester.ac.uk }}$

9

10 


\section{SUMMARY}

12 Soil microbial communities play a pivotal role in regulating ecosystem 13 functioning $^{1}$ but they are increasingly threatened by human-driven perturbations, 14 including climate extremes, which are predicted to increase in frequency and intensity

15 with climate change ${ }^{2}$. It has been demonstrated that soil microbial communities are 16 sensitive to climate extremes, such as drought ${ }^{3,4}$, and that effects can be long-lasting ${ }^{5,6}$.

17 However, considerable uncertainties remain concerning the response of soil microbial 18 communities to increases in the intensity and frequency of climate extremes, and their 19 potential to trigger transitions to alternative, and potentially deleterious, taxonomic and 20 functional states ${ }^{7}$. Here we demonstrate that extreme, frequent drought induces a shift to 21 an alternative soil microbial state characterised by strongly altered bacterial and fungal 22 community structure of reduced complexity and functionality. Moreover, we found that 23 this drought-induced alternative microbial state persisted after returning soil to its 24 previous moisture status. However, bacterial communities were able to adapt by 25 increasing their growth capacity, despite being of reduced diversity. Abrupt transitions 26 to alternative states are well documented in aquatic and terrestrial plant communities in 27 response to human-induced perturbations, including climate extremes ${ }^{8,9}$. Our results 28 provide experimental evidence that such transitions also occur in soil microbial 29 communities in response to extreme drought with potentially deleterious consequences 30 for soil health.

\section{MAIN}

Natural ecosystems are constantly exposed to natural fluctuations in environmental 34 conditions and under such conditions they retain a stable equilibrium state, or quasi- 
35 stable state, characterized by minor fluctuations in community composition and

36 function ${ }^{10}$. However, human-induced perturbations, such as those related to climate

37 change, can destabilise this dynamic equilibrium and potentially trigger a cascade of

38 events that may lead to an abrupt change from one ecosystem state to another ${ }^{8}$. Abrupt

39 transitions occur when an ecosystem moves from one attraction basin into a different

40 one in its stability landscape after surpassing a certain threshold ${ }^{8}$. This can have

41 important consequences for ecosystem functioning, as the ecosystem stays in the new

42 attraction valley - the alternative state - even if the perturbation that triggered the

43 change has ceased. Numerous studies have demonstrated the existence of abrupt

44 changes to alternative states in aquatic ecosystems ${ }^{9,11}$, terrestrial plant communities ${ }^{12,13}$,

45 and the human gut microbiome in response to perturbations ${ }^{14,15}$. However, abrupt

46 transitions to alterative states in soil microbial communities have so far received little

47 attention $^{7}$, despite their fundamental role in terrestrial ecosystems, driving key processes

48 of organic matter decomposition, nutrient cycling, and carbon and nutrient storage ${ }^{16}$,

49 which regulate ecosystem productivity. As such, abrupt transitions in soil microbial

50 communities from one state to another may have significant implications for soil

51 functioning, with consequences for ecosystem services, such as food production and

52 climate regulation ${ }^{1}$.

53 Soil microbial communities are increasingly challenged by perturbations associated

54 with human-induced environment change, including intense 'pulse' perturbations ${ }^{17}$

55 caused by climate extremes (e.g. droughts, heat waves and floods), which are predicted

56 to increase in frequency and intensity as a consequence of ongoing climate change ${ }^{2}$.

57 Previous studies have shown that soil microbial communities are sensitive to drought,

58 with different microbial groups varying in their tolerance and ability to recover from

59 drought $^{3,18,19}$. Moreover, extreme drought has been shown to de-stabilize soil bacterial 
60 networks, potentially rendering them more vulnerable to subsequent drought ${ }^{20}$, although

61 repeated droughts can also lead to soil microbial communities becoming more resistant

62 to drought ${ }^{5,21,22}$. Extreme drought has been shown to shift peatland moisture

63 characteristics $^{23}$ and plant-soil fungi interactions ${ }^{24}$ to an alternative state, and repeated

64 dry-wet cycles induced shifts in the functional state of agricultural soils, measured as

65 soil respiration ${ }^{25}$.However, evidence of transitions to alternative states in soil microbial

66 communities in response to perturbations, such as drought, is still lacking. Specifically,

67 it remains unresolved whether increases in the intensity and frequency of drought has

68 potential to trigger an abrupt change in soil microbial communities to an alternative taxonomic and functional microbial state.

Here, we experimentally tested whether increases in the intensity and frequency of

71 drought triggers a shift to an alternative, functionally deleterious state in soil microbial

72 communities. Petraitis and Dugeon ${ }^{26}$ proposed that experimental evidence of the

73 existence of alternative stable states must fulfil three conditions: it must (a) demonstrate

74 that communities differ significantly in their assembly and functional attributes within

75 the same environment; (b) vary with the scale of the pulse perturbation, given that small

76 perturbations are likely to be insufficient to tip the system from one state to another,

77 whereas large perturbations are more likely to do so; and (c) be carried out over a

78 sufficient time period to ensure that the alternative states are self-sustaining or stable.

79 To meet these conditions, and experimentally test for the existence of alternative states

80 in soil microbial communities, we carried out an incubation experiment in a plant-free

81 system whereby we imposed a matrix of drought frequency and intensity treatments

82 (one, two, three drought events and mild, intermediate and extreme drought,

83 respectively), followed by the assessment over an extended period of time of a broad

84 range of taxonomic and functional attributes of microbial communities in a natural 
85 grassland soil. The experimental system, although simplified, allowed us to provide

86 experimental proof of concept of the existence of alternative states in soil microbial

87 communities. We discovered that high intensity drought triggered a shift to an

88 alternative microbial state of reduced structural complexity and impaired functioning.

89 We also discovered that the functional characteristics of soil microbial communities

90 could adapt to drought exposure, revealing a faster ability of bacterial communities to

91 recover growth rates following drought in the alternative state.

\section{Changes in microbial community structure}

93 Our findings show that extreme drought $(\sim 11 \% \mathrm{WHC})$, simulating a once in a

94 century drought in England (see methods), had a profound and long-lasting impact on

95 soil microbial community structure and diversity, despite environmental conditions

96 being returned to their original state (optimum moisture, 65\% WHC). Six months after

97 the end of the extreme drought, bacterial diversity (Fig 1a, b) was still reduced, while

98 fungal Shannon diversity was significantly higher than in the non-droughted control

99 treatment (Fid. 1d), despite no effects on fungal species richness being detected (Fig.

100 1c). These contrasting responses (reduced bacterial diversity but increased fungal one)

101 are consistent with previous findings ${ }^{20,27}$. Bacterial and fungal community structure was

102 strongly affected by drought (Fig. 1e, f, Extended Data Fig.1a, b) and changes in

103 microbial community structure observed after drought were exacerbated with time. This

104 is exemplified in the proportion of variance in community structure explained by

105 drought intensity (Fig. 1g), which increased after 6 months compared to immediately

106 after drought, particularly under the extreme drought treatment. However, bacterial

107 communities in soils subjected to intermediate (23\% WHC) drought, which simulated

108 drought events in England occurring every 4 years, partially recovered (Fig. 1g), with

109 less variance explained by drought treatments after 6 months than after drought, i.e., 
they were more similar to the control treatments after 6 months than at the end of the

111 perturbation. Mild drought (40\% WHC), which simulated common drought events

112 occurring annually in England, had no detectable impact on microbial community

113 structure. Drought frequency also significantly affected bacterial and fungal community

114 structure (Fig. 1e, f), with those soils exposed to more frequent drought being more

115 distinct from the non-droughted control and soil subject to fewer drought events.

116 Sixty-eight of the 82 indicator genera identified for bacteria (Extended Data Fig. 2a)

117 were indicators for all of the groups except the extreme drought, i.e. their abundance

118 was significantly reduced under extreme drought. The proportion of different bacterial

119 taxa observed in the soil communities was mainly affected by drought intensity and

120 time, with some minor effects of drought frequency (Extended Data Table 1). Bacterial

121 phyla Proteobacteria, Actinobacteria and Firmicutes increased in relative abundance

122 with drought intensity, while Acidobacteria and Bacteroidetes decreased (Extended

123 Data Fig. 1c). There was a clear shift in the bacterial community, persistent through

124 time, from a community co-dominated by Acidobacteria and Proteobacteria in the

125 control towards one dominated by Proteobacteria under extreme drought. Some of these

126 Phyla-level responses were consistent with previous reports. Actinobacteria ${ }^{18,21}$ and

127 Firmicutes ${ }^{28,29}$ have been frequently reported as drought tolerant. However, there are

128 contrasting references to Proteobaceria, with some studies defining them as tolerant to

129 drought $^{5}$, and others showing a decrease in their abundance after drought ${ }^{27}$. On the other

130 hand, Acidobacteria ${ }^{18}$ and Bacteroidetes ${ }^{27}$ have been described as sensitive to drought,

131 as found in this study, although there are also some contradictory reports in the

132 literature for both phyla ${ }^{5,30}$.

133 At family level, particularly significant were the increases in Xanthobacteraceae,

134 Chthoniobacteraceae, Rhodanobacteraceae and a transient increase in Burkholderiaceae 
135 after drought (Fig. 1h), and the decrease in the relative abundance of Solibacteraceae

136 and Pedosphaeraceae with drought intensity (Fig. 1h). An increase in

137 Xanthobacteraceae in soils under drought stress has been previously reported ${ }^{31}$. Within

138 the family Chthoniobacteraceae, the most abundant genus was Candidatus

139 Udaeobacter. This is an extremely abundant genus in soils, adapted to grow efficiently

140 under limited resources ${ }^{32}$, which could be the case in the drought exposed soils of this

141 experiment.. The Rhodanobacteraceae family was dominated by the genus

142 Rhodanobacter. This genus is common in soils and some species have been identified

143 as plant growth promoting rhizobacteria with drought protection capacities ${ }^{33}$. Finally,

144 the transient increase in Burkholderiaceae after drought was mostly driven by an

145 increase in the genus Massilia. They have been identified as copiotrophic bacteria that

146 can quickly grow under high nutrient conditions (such as those created at rewetting) but

147 that lose their competitive advantage later on $^{34}$, which can explain the pattern observed

148 in this experiment. Regarding those families that decreased with drought, both agree

149 with the literature, as Solibacteraceae ${ }^{18}$ and Pedosphaeraceae $e^{35}$ have been found to 150 decrease with decreasing soil moisture.

151 Fungal indicator genera (Extended Data Fig. 2b) were mostly identified for the 152 control + mild + intermediate drought group (17 out of 20$)$, with no genus indicator for 153 the extreme drought. The relative abundance of main fungal phyla was mostly affected 154 by drought intensity and time (Extended Data Fig. 1e, Extended Data Table 1). We 155 observed an increase in Ascomycota and a decrease in Mortierellomycota. In particular, 156 we observed an increase in relative abundance of Piskurozymaceae, Helotiales, 157 Trimorphomycetaceae and Nectriaceae, and a substantial decrease of Mortierellaceae 158 and Clavariaceae, the two most abundant fungal families (Fig. 1i), which are both 159 typical soil saprotrophs. In agreement with this, we observed a significant decrease with 
160 drought treatments in the relative abundance of taxa considered as saprotrophs

161 (Extended Data Fig. 1g). Therefore, the observed increase in fungal diversity (Shannon 162 index, Fig. 1d) was not associated with a change in species richness, but with an 163 increase in evenness, as a result of decreasing abundances of the two major fungal taxa, 164 Mortierellaceae and Clavariaceae. These two families have been previously identified as 165 drought sensitive ${ }^{20,36}$. The observed effects could be related to the changes in nutrient 166 availability elicited by drought (see section below). Fungi are generally considered to be 167 more resistant to drought than bacteria ${ }^{20,37}$ and several studies demonstrate a lack of 168 drought effect on fungal communities ${ }^{3}$. In contrast, we observed a clear change in the 169 fungal communities, which was still evident 6 months after returning droughted soils to 170 their original, pre-drought moisture content.

171 Bacterial diversity is strongly affected by soil $\mathrm{pH}$ at a global scale ${ }^{38}$ and at local 172 scales $^{39}$, while its impact on fungal diversity is weak or absent. In our experiment, 173 bacterial diversity and community structure were correlated with a decrease in soil $\mathrm{pH}$ 174 at the last sampling point (Extended Data Fig. 3a-c), associated with increased nitrate 175 ion concentrations at this sampling time (Extended Data Fig. 3f). In agreement with the 176 literature ${ }^{39,40}$, fungal diversity was only marginally affected by soil $\mathrm{pH}$ (Extended Data 177 Fig. 3d-e).

\section{Changes in microbial community function}

Our data show that microbial community shifts in response to extreme drought were associated with persistent changes in microbial functioning (Extended Data Fig. 3g-h).

181 Soils exposed to extreme drought were in a significantly different functional state than 182 the control soils even 6 months after the end of the perturbation (Fig. 2c, d). 
After the end of drought, when soils were rewetted to the level of the control, seven

184 of the eight extracellular enzyme activities evaluated were significantly reduced by drought intensity and/or frequency, displaying a low resistance to drought (Fig. 2a, Extended Data Fig. 4a-h, Extended Data Table 2). Phenoloxidase (POX) activity was slightly reduced by all drought treatments compared to the control, with no significant effect of drought intensity or frequency levels (Fig. 2a, Extended Data Fig. 4g). Only the activity of peroxidase (PER) was not affected by drought (only a marginal effect of drought frequency) (Extended Data Fig. 4h). The effects of drought intensity on soil enzymes were still detectable after six months (Extended Data Fig. 4i-p), with very little or no resilience, or even a stronger reduction of their activity than immediately after drought (phosphatase) (Fig. 2b), manifesting a persistent reduction of soil functional capacity; a functional regime shift. A reduction in soil enzymatic capacity with drought has been frequently reported ${ }^{41}$, probably associated with microbial death and thus reduced enzyme production, and reduced substrate diffusion that limits enzyme activity $^{42}$. However, these effects are quite context dependent ${ }^{41}$ and some authors have reported increased enzyme activities under drought ${ }^{43,44}$, which could be related to a reduced degradation rate of soil enzymes and accumulation during dry periods ${ }^{42}$. In our experiment, enzyme activities correlated with available nutrients (Extended Data Fig. 3i-k). Additionally, consistently low microbial biomass after 6 months (Fig. 2b, 202 Extended Data Fig. 31) could explain the lack of recovery of enzymatic capacities. 203 Ligninases (POX and PER) were less affected by drought than the hydrolytic enzymes, 204 which could be related to the fact that fungal communities were less affected by drought 205 than bacterial ones, as ligninases are mostly produced by fungi ${ }^{42}$.

206 Soil nutrients were highly affected by drought, particularly available ammonium and 207 DOC, with a significant increase due to drought intensity and frequency and an 
208 interaction between them: the more intense the drought, the bigger the effect of drought

209 frequency on their concentration (Fig. 2a, Extended Data Fig. 5a-f, Extended Data Table

210 2). Increases in nutrient availability after rewetting dry soils have been frequently

211 explained by the death of microorganisms and the fact that some organic compounds in

212 the soil become more available after drought ${ }^{45,46}$. On the other hand, soil nitrate

213 concentrations were reduced with most drought treatments compared to the control,

214 showing a low resistance (Fig. 2a). After six months, this big ammonium and DOC

215 flush had mostly disappeared and in turn, nitrate levels significantly increased (Fig. 2b,

216 Extended Data Fig. 5k-p). This could be related to a high nitrification activity, where

217 the highly abundant ammonium was transformed into nitrate ${ }^{47}$.

218 Microbial biomass $\mathrm{C}, \mathrm{N}$ and $\mathrm{P}$ were reduced by increasing drought intensity, and this

219 effect was still detected after 6 months of returning soils to moisture levels of the

220 control, with microbial P in extreme drought treatments showing a stronger decrease

221 with time (Fig 2b, Extended Data Fig. 5g-i, q-s, Extended Data Table 2). Decreases in

222 microbial biomass due to drought have been widely reported ${ }^{27,48}$, although some authors

223 observed an increase in microbial biomass under drought ${ }^{49}$. The constant decline of

224 microbial P over time could be related to reduced phosphatase activity (Extended Data

225 Fig. 3m). This is in agreement with the study of Dijkstra and collaborators ${ }^{50}$ that

226 showed a strong reduction in microbial $\mathrm{P}$ uptake under drought. However, a decrease in

227 microbial biomass over time in bare soils is expected, as there is no additional $\mathrm{C}$ input

228 from plants into the system.

229 Adaptation of microbial growth characteristics to drought

230 Our assessment of the responses of microbial communities with a history of drought

231 to a further drying/rewetting cycle helped us examine legacy effects of drought and 
232 adaptation of growth responses, as a community, of bacteria and fungi. Drought 233 intensity had a legacy effect resulting in shorter lag times and higher cumulative growth

234 (Fig. 3a, b) after rewetting, indicating a faster recolonization ability. The increased and 235 faster bacterial growth in soils with a drought history has been previously observed ${ }^{22}$, 236 and can be a good adaptive strategy in soils exposed to frequent drought events. On the 237 other hand, cumulative fungal growth (Fig. 3c) significantly decreased with previous 238 drought intensity, which could underpin the reduced abundance of the two dominant 239 fungal families. This result contrasts with other studies where fungal growth was not 240 affected by drought history ${ }^{19,51}$. However, the fungal growth capacity in our study could 241 have also been constrained by the high bacterial growth in the soils ${ }^{52}$. These effects on 242 microbial growth were not dependent on the microbial biomass of soils before 243 drying/rewetting (Extended Data Fig. 3n,o). Cumulative respiration after rewetting 244 significantly decreased with previous drought intensity (Fig. 3d), and thus it seems to be 245 driven by fungi, as it follows approximately the same pattern as cumulative fungal 246 growth. This contrasts with some recent observations, where respiration was mostly 247 driven by bacterial growth ${ }^{19}$. Alternatively, this decrease in cumulative respiration with 248 previous drought intensity could be also related to resource availability. Previous 249 extreme drought led to a strong increase of DOC, which was mostly used one month 250 after drought, and this likely depleted the soil carbon available to fuel a respiration peak 251 after the additional drying/rewetting cycle. Reduced carbon availability in soils after 252 drought has been previously reported ${ }^{47}$, as well as less intense respiration peaks after 253 repeated drying/rewetting cycles ${ }^{22,47}$.

254 Fungi were more resistant to low moisture than bacteria, as shown by the $\mathrm{IC}_{10}$ 255 (moisture level at which growth rate is reduced by 10\%), but this was not significantly 256 affected by previous drought treatments (Extended Data Fig. 6). However, there were 
257 some trends evident, with bacteria and fungi responding in opposite directions. While

258 previous exposure to drought had a tendency to reduce bacterial resistance to drought

259 (higher IC values), fungi tended to show a higher resistance to drought under some of

260 the previous treatments (lower IC values), although this was quite variable. Respiration

261 showed reduced resistance to drought with previous drought intensity.

262 We observed legacy effects of drought on soil microbial communities, as previously

263 described. For example, pre-exposure to drought has been demonstrated to increase 264 bacterial resistance ${ }^{5,21}$ and resilience ${ }^{22}$ to subsequent droughts, although others have 265 reported the opposite pattern, with previous drought damaging microbial communities 266 in the long-term ${ }^{20,27}$. We observed an increased recolonization capacity of bacteria, 267 albeit a lower tolerance to reduced soil moisture, while fungi showed a potential 268 increased resistance to drought but with less cumulative growth upon rewetting. Thus, 269 there seems to be a trade-off between growth after rewetting, which can be interpreted 270 as resilience, and resistance to low moisture, as previously proposed ${ }^{53}$. These strategy 271 changes could be the result of a shift in the relative abundance of different taxa within 272 the community or due to changes in individual taxa's physiology or traits (evolution). In 273 any case, the response of fast re-coloniser bacterial taxa appears to shape bacterial 274 communities after drought, as they occupy empty niches left after drought, conditioning 275 community assembly afterwards ${ }^{54}$.

\section{Drought threshold and shift to alternative state}

Our findings provide experimental evidence that the harshness of drying determined the response pattern of microbes upon rewetting. Although gradient designs are best suited to evaluate thresholds ${ }^{55}$, the design of the present experiment with four levels of 
281 microbial state at a water content of $\sim 15 \%$ WHC ( 9\% volumetric soil water content),

282 which corresponds to a 30 year recurrent drought event in England (Extended Data Fig.

283 6d-g). Below this moisture level, soil microbial communities were considerably and 284 persistently restructured with impaired functioning, and they failed to recover over a 285 period of 6 months, despite returning moisture levels to those of the control. The 286 existence of this threshold is further supported by a previous study that demonstrated 287 that below a threshold of $14 \%$ WHC, the growth pattern of bacteria upon rewetting 288 changed significantly ${ }^{56}$

To further evaluate potential shifts to alternative states in our experiment, we mapped microbial community composition and function with multivariate analysis, as it is a useful tool to visualise stability landscapes and regime shifts ${ }^{57}$. We observed a clear pattern in both community structure and function of soil microbial communities where soils subjected to extreme drought occupy a clearly distinct space separated from the control, which can be interpreted as an alternative basin in the stability landscape, an alternative state of the system (Extended Data Fig. 6h-k). Moreover, our experiment met most of the recognised criteria for detecting an alternative state $^{26}$. First, we demonstrated the existence of two different microbial communities given the same environmental condition (optimum soil moisture during the period after drought). Second, different intensities of drought (different scale of pulse perturbation) were found to have contrasting effects on soil microbial communities, with mild and intermediate drought showing reversible effects, but persistent changes in response to extreme drought. Third, our experiment was conducted over an extended period of time, representing the typical length of the growing season in the north of England, where the 304 soil samples were collected. The identified microbial shifts are unlikely to represent a 305 "stable" alternative state. Nevertheless, we experimentally demonstrate that microbial 
306 communities subject to extreme drought shift towards a different state that is distinct

307 from its original one and also from the non-droughted control soils. Therefore, we

308 propose that the detected microbial shifts reflect an alternative "transient" $\operatorname{state}^{54}$ or

309 simply an alternative state.

\section{Conclusion}

311 Our findings experimentally demonstrate that extreme and frequent drought triggers

312 a shift to an alternative microbial state, with pronounced and persistent reduction in soil

313 microbial community functional capacity, modified taxonomical composition of

314 reduced complexity, and faster ability of bacterial communities to recover growth rates

315 following drought. Moreover, we show that this state transition was driven by drought

316 intensity and occurred at a threshold of $\sim 15 \%$ WHC, although more frequent and

317 extreme events produced stronger effects than milder and less frequent drought events.

318 Future studies are needed to consider the role of extrinsic factors that might modify the

319 vulnerability of soil microbial communities to drought-induced transitions to alternative

320 states, such as the presence of plants, which can help the system recover after drought ${ }^{58}$,

321 or differences in nutrient availability and other soil abiotic properties ${ }^{7}$. Nevertheless, our

322 results provide experimental evidence for the existence of alternative taxonomic and

323 functional states in soil microbial communities driven by extreme drought, with

324 potentially deleterious consequences for soil health. 


\section{METHODS}

\section{Soil collection and experimental design}

A pot experiment was designed to test the effects of drought intensity and frequency

329 (3 levels each, full-factorial including a well-watered control), on the microbial 330 communities in grassland soils. Soils were collected in Selside, Yorkshire Dales (54.17

$331 \mathrm{~N}, 2.34 \mathrm{~W})$, from four independent plots (replicates). Turf was removed $(2-3 \mathrm{~cm})$, and

332 topsoil collected from 3-10 cm depth. Main soil characteristics are shown in Extended

333 Data Table 3. Soils were sieved (4 mm mesh) and divided into pots $(8 \mathrm{~cm}$ height, $8 \mathrm{~cm}$

334 diameter, and $170 \mathrm{ml}$ volume $)$, filled to mimic the mean field bulk density $\left(0.82 \mathrm{~g} \mathrm{~cm}^{-3}\right)$.

335 Pots were incubated at $18{ }^{\circ} \mathrm{C}, 30 \%$ air relative humidity, and kept at $65 \%$ water holding 336 capacity (WHC), which correspond to $40 \%$ volumetric water content. After 3 weeks of 337 stabilisation, drought treatments were applied by different watering regimes: control 338 treatments received $100 \%$ of the water loss, mild drought treatments received $2 / 3$, 339 intermediate drought received $1 / 3$ and extreme drought received no water. Pots were 340 watered every other day with autoclaved water. Soil moisture was evaluated 341 gravimetrically. Drought lasted 2 weeks followed by 2 weeks of recovery when pots 342 were slowly rewetted to optimum moisture (65\% WHC). Drought was repeated up to 3 343 times depending on the drought frequency treatment. Control pots were always kept at $34465 \%$ WHC. Drought levels were compared for contextualisation to historical data of soil 345 moisture (1991-2020) in England, made available by the CCI SM project ${ }^{59,60}$. Minimum 346 annual values of soil moisture were fitted to an extreme value distribution (Gumbel 347 distribution) with the package "extRemes" ${ }^{\prime 61}$. The maximum drought experienced by 348 treatments in each cycle was approximately $40 \%$ WHC for mild drought ( 23\% 349 volumetric water content), which corresponded to the average values of soil moisture 350 during the summer (Jun-Aug), 23\% WHC for intermediate drought ( $14 \%$ volumetric 
351 water content), which resembled common summer drought events (once every 4 years),

352 and $11 \%$ WHC for extreme drought ( $7 \%$ volumetric water content), which simulated a

353 once in a century drought. Extended Data Fig. 7a summarizes the evolution of WHC.

354 WHC capacity was affected by the drought treatments (Extended Data Fig. 7b), so after

355 each drought cycle, WHC was re-evaluated. The decrease of moisture retention capacity

356 of soils after repeated drought has previously been documented ${ }^{23,62}$.

357 Immediately after the last drought cycle, samples were collected to evaluate the

358 resistance of the system. We consider the perturbation the entire drying/rewetting cycle, 359 and thus, to evaluate the resistance we harvested the pots once the perturbation had 360 ended (when all pots recovered the same WHC, 11 days after the start of the rewetting, 361 Extended Data Fig. 7a). Additionally, pots were harvested over time, to evaluate the 362 resilience of the system in the long term (1, 3 and 6 months after drought), which covers 363 the length of the typical growing season for the study sites where soil was collected in 364 the Yorkshire Dales (Met Office UK). 40 extra pots were harvested 1 month after 365 drought to evaluate the adaptation of microbial growth characteristics to drought. Total 366 number of pots: 200.

\section{Microbial community structure}

Soil samples were collected in Eppendorf tubes (approx. $0.25 \mathrm{~g}$ ) and frozen at $-80{ }^{\circ} \mathrm{C}$ 369 just after sampling. DNA was extracted in frozen samples, without thawing, with 370 PowerSoil DNA isolation Kit (Qiagen, Germany). DNA was sent to Macrogen 371 sequencing service (Macrogen Inc., Korea), for Illumina sequencing (MiSeq v3). Fungal 372 diversity was evaluated by ITS2 sequencing, using the primer pair 5.8S-Fun and ITS4373 Fun $^{63}$. Bacterial diversity was evaluated by $16 \mathrm{~S} \mathrm{V3-V4}$ sequencing, with primers 374 Bakt_341F and Bakt_805R ${ }^{64}$. Microbial community analysis was not done in samples 
375 from the 3 months after drought time point. Alongside the samples, three extraction

376 blanks were included and a mock community sample for each primer pair: 19 strains

377 genomic DNA even mix from Bakker lab for fungi ${ }^{65}$, and MSA-1000 ${ }^{\mathrm{TM}} 10$ strain even

378 mix genomic material for bacteria from the American Type Culture Collection (ATCC,

379 Manassas, US).

380 The quality of sequences was assessed using FASTQC ${ }^{66}$. Primers were removed 381 using cutadapt $^{67}$ (fungi) or obitools ${ }^{68}$ (bacteria). Low quality areas at the end of the 382 reads were trimmed using truncLen $=\mathrm{c}(275,200)$ (fungi) or truncLen $=\mathrm{c}(260,180)$ plus

38310 additional nucleotides at the beginning of forward reads (bacteria). Sequences were 384 analysed using the DADA2 pipeline ${ }^{69}$ with default parameters, except maxEE for fungi 385 which was set to 4 in each direction. After filtering and de-noising steps $77 \%$ (fungi) or $38644 \%$ (bacteria) of the reads were retained, and 4,227 (fungi) or 16,924 (bacteria) 387 amplicon sequence variants (ASV) were identified. Taxonomic identification was 388 performed by IDTAXA taxonomic classification method in DECIPHER ${ }^{70}$ package 389 using UNITE reference database (sh_general_release_dynamic_s_01.12.2017.fasta) for 390 fungi and SILVA database (SILVA_SSU_r132_March2018.RData) for bacteria. 391 Database was refined by four consecutive steps. 1) Renormalization to counteract the 392 problem of tag-switching ${ }^{71}$ : for the abundant ASVs ( $\geq 100$ reads), eliminate the reads of 393 the samples corresponding to a cumulative frequency of less than $3 \%$ for each particular 394 ASV. 2) Lulu algorithm to reduce the number of erroneous ASVs and achieve more 395 realistic biodiversity metrics ${ }^{72}$, setting the minimum ratio at 2 for fungi and minimum 396 match at $99 \%$ for bacteria, and the rest parameters set as default. The election of these 397 parameters was based on the results of the mock community sample. 3) Minimal 398 abundance filtering, by removing any reads that represent $<0.02 \%$ abundance in each 399 sample. 4) Blank correction, where ASVs were removed if the total abundance in blanks 
400 divided by the total abundance in sample was greater than $10 \%$, in each particular ASV.

401 Finally, only fungi or bacteria sequences were retained. For fungal database, other 402 eukaryotic reads that were removed represented the $0.01 \%$ of the reads. For bacteria, 403 taxa unclassified at domain level represented the $2.69 \%$ of the reads, Archaea reads 404 represented the $0.004 \%$ and chloroplast sequences represented the $0.0007 \%$. All of them 405 were removed. Final databases contained 2,760 ASVs and 4,316,693 reads for fungi, 406 and 7,198 ASVs and 2,392,480 reads for bacteria. Sampling depth varied from 25,87340753,007 (mean 36,275) reads in fungi and 12,595-58,150 (mean 19,937) reads in 408 bacteria, and it was equally distributed among drought treatments. Rarefaction curves were plotted using the rarecurve function in "vegan", ", and these indicated that sampling depth was sufficient for all samples, plateauing at around 7,500 reads.

\section{Soil enzymes}

$412 \quad \beta$-glucosidase $(\mathrm{GLC}), \quad$ cellobiohydrolase $\quad(\mathrm{CBH}), \quad$ xylosidase $\quad(\mathrm{XYL}), \quad N-$ 413 acetylglocasiminidase (NAG) and acid phosphatase (PHO) were measured 414 photometrically according to Jackson et al. $2013^{74}$, with modifications. $3.75 \mathrm{~g}$ of sieved 415 soil was suspended in $5 \mathrm{~mL}$ of sodium acetate buffer $(50 \mathrm{mM}, \mathrm{pH} 5.0) .150 \mu \mathrm{l}$ of soil 416 slurry were introduced into a 96-well deepwell block and mixed with $150 \mu \mathrm{l}$ of a 417 saturating substrate solution: $25 \mathrm{mM} p \mathrm{NP}-\beta$-glucopyranoside for GLC, $2 \mathrm{mM} p \mathrm{NP}-\beta$-D418 cellobioside for $\mathrm{CBH}, 25 \mathrm{mM} p \mathrm{NP}-\beta$-xylopyranoside for XYL, $5 \mathrm{mM} p \mathrm{NP}-\mathrm{N}$-acetyl- $\beta$ 419 D-glucosaminide for NAG and $5 \mathrm{mM} p$ NP-phosphate disodium salt hexahydrate for 420 PHO. Plates were incubated at $18{ }^{\circ} \mathrm{C}$ for $0.5 \mathrm{~h}$ (PHO), $1.5 \mathrm{~h}$ (GLC), $3.5 \mathrm{~h}$ (XYL and $421 \mathrm{NAG})$ or $4 \mathrm{~h}(\mathrm{CBH})$ under continuous shaking. Blocks were centrifuged $(2900 \mathrm{~g}, 5$ $422 \mathrm{~min}), 100 \mu \mathrm{l}$ of the supernatant pipetted into transparent 96-well plates and mixed with $423200 \mu \mathrm{l}$ of $50 \mathrm{mM} \mathrm{NaOH}$ solution. Absorbance was measured at $405 \mathrm{~nm}$ in a plate reader 
424 (EZ400 Research, Biochrom, Germany) and corrected for soil and substrate colouration.

425 Reported activity is the mean of four analytical replicates.

426 Urease (URE) was measured by the optimised high throughput method ${ }^{75}$ without 427 modifications. Absorbance was evaluated in a microplate reader (EZ400 Research,

428 Biochrom, Germany) and reported activity is the mean of four analytical replicates.

429 Phenoloxidase (POX) and peroxidase (PER) activities were measured photometrically

430 following Sinsabaugh \& Linkins $1988^{76}$ method, with modifications. $0.25 \mathrm{~g}$ of soil were

431 suspended in $25 \mathrm{ml}$ of sodium acetate buffer $(50 \mathrm{mM}, \mathrm{pH} 5.0) .0 .4 \mathrm{ml}$ of soil slurry were

432 extracted under continuous shaking and mixed (1:1) with a $20 \mathrm{mM}$ L-3,4-

433 dihydroxyphenylalanin ( ${ }_{\mathrm{L}}$-DOPA) solution in a deep-well block. Blocks were shaken for

$43410 \mathrm{~min}$ and centrifuged $(2900 \mathrm{~g}, 5 \mathrm{~min}) .250 \mu \mathrm{l}$ of the supernatant were pipetted into

435 transparent 96-well plates. For peroxidase activity, wells additionally received $10 \mu \mathrm{l}$ of

436 a $0.3 \% \mathrm{H}_{2} \mathrm{O}_{2}$ solution. Absorbance was measured at $450 \mathrm{~nm}$ in a plate reader (EZ400

437 Research, Biochrom, Germany) at the starting time point $\left(\mathrm{t}_{0}\right)$, after $1.5 \mathrm{~h}\left(\mathrm{t}_{1}\right.$ for PER)

438 and after $20 \mathrm{~h}\left(\mathrm{t}_{1}\right.$ for POX) at $18^{\circ} \mathrm{C}$. Enzyme activity was calculated from the difference

439 in absorption between the two time-points divided by L-DOPA molar extinction

440 coefficient $\left(7.9 \mu \mathrm{mol}^{-1}{ }^{77}\right)$. For PER activity, POX activity was subtracted. Reported

441 activity is the mean of three analytical replicates.

\section{$442 \quad$ Nutrient pools}

443 Different nutrient pools were measured by means of soil extractions with different 444 extracting solutions depending on the nutrient and the pool of interest ${ }^{78}$. All soil 445 nutrients were evaluated in duplicates, and reported values are the mean of those two 446 analytical replicates. Dissolved organic carbon (DOC) and dissolved organic nitrogen 447 (DON) were evaluated in water extracts (5 g soil in $28 \mathrm{ml}$ MiliQ water) and plant 
448 available nitrogen (ammonium and nitrate) were evaluated in $\mathrm{KCl}$ extracts $(2.5 \mathrm{~g}$ soil in

$449 \quad 12.5 \mathrm{ml} 1 \mathrm{M} \mathrm{KCl})$. In both cases, soil with extracting solutions were horizontally shaken

450 at $200 \mathrm{rpm}$ for 30 minutes and filtered through Whatman $\mathrm{n}^{\circ} 42$ filter papers $(\mathrm{KCl}$

451 extracts) or $0.45 \mu \mathrm{m}$ syringe filters ( $\mathrm{H}_{2} \mathrm{O}$ extracts). $\mathrm{N}$ pools were measured in AA3 HR

452 Auto Analyser (Seal Analytical, UK) while C pools were measured in 5000A TOC-L

453 analyser (Shimadzu, Japan). Plant available P was extracted with acetic acid solution (1

$454 \mathrm{~g}$ soil $+25 \mathrm{ml} 2.5 \%$ acetic acid) and detected by molybdate colorimetry using AA3 HR

455 Auto Analyzer (Seal Analytical, UK).

456 Organic $\mathrm{P}$ was estimated by evaluation of available phosphate before and after 457 sample ignition ${ }^{79}$. Two portions of dry soil $(2 \mathrm{~g})$ were weighed. One of them was burned

458 at $550^{\circ} \mathrm{C}$ for $4 \mathrm{~h}$ in a furnace. Afterwards, both samples were extracted with $50 \mathrm{ml} 0.5 \mathrm{M}$

$459 \mathrm{H}_{2} \mathrm{SO}_{4}$ by horizontally shaking at $120 \mathrm{rpm}$ for $16 \mathrm{~h}$. Extracts were filtered (Whatman

460 No. 42) and phosphate was evaluated by the ascorbic acid method ${ }^{79}$. After sample

461 neutralization with $\mathrm{NaOH}$, the colour reaction was carried out and the amount of blue

462 was evaluated by absorbance at $880 \mathrm{~nm}$ in a CLARIOstar plate reader (BMG Labtech,

463 Germany).

464 Microbial biomass $\mathrm{C}$ and $\mathrm{N}$ was measured using the fumigation-extraction 465 techniques ${ }^{80,81} \cdot 2.5 \mathrm{~g}$ of soil were fumigated with $\mathrm{CHCl}_{3}$ for $24 \mathrm{~h}$. Soluble $\mathrm{C}$ and $\mathrm{N}$ were 466 extracted from the fumigated and from un-fumigated samples with $12.5 \mathrm{ml} 0.5 \mathrm{M}$ $467 \mathrm{~K}_{2} \mathrm{SO}_{4}$. Soil + extracting solution were shaken and filtered (Whatman No. 42) and total $468 \mathrm{C}$ and $\mathrm{N}$ were analysed in TOC and AA, respectively. Microbial $\mathrm{C}$ and $\mathrm{N}$ flush 469 (difference between fumigated and un-fumigated samples) were converted to microbial 470 biomass using $\mathrm{k}_{\mathrm{EC}}$ factor of $0.35^{82}$ and $\mathrm{k}_{\mathrm{EN}}$ factor of $0.54^{80}$.

471 Microbial P was estimated with the hexanol fumigation and extraction with anion472 exchange membranes method ${ }^{83}$. Membrane strips $(1 \times 4 \mathrm{~cm})$ were prepared by shaking 
473 in $0.5 \mathrm{M} \mathrm{NaHCO}_{3}$. For each sample, three portions of fresh soil (2 g) were weighed into

$47450 \mathrm{ml}$ tubes: unfumigated, fumigated and spiked samples. In each tube, $30 \mathrm{ml}$ deionized

475 water and three anion-exchange membrane strips were added. Fumigated samples

476 received $1 \mathrm{ml}$ of hexanol while spiked samples received $1 \mathrm{ml}$ of a $20 \mathrm{mg} \mathrm{ml}^{-1} \mathrm{P}$ solution.

477 All tubes were shaken for $24 \mathrm{~h}$. The membranes were then removed and rinsed with

478 deionized water and phosphate recovered by shaking for $1 \mathrm{~h}$ in $20 \mathrm{ml}$ of $0.25 \mathrm{M} \mathrm{H}_{2} \mathrm{SO}_{4}$,

479 with detection at $880 \mathrm{~nm}$ by automated molybdate colorimetry using AA3 HR Auto

480 Analyzer (Seal Analytical, UK). Microbial phosphorus were calculated as the difference

481 between the fumigated and un-fumigated samples, corrected by the sorption percentage

482 (spiked samples) and transformed using a $\mathrm{k}_{\mathrm{EP}}$ factor of $0.40^{84}$.

483 Adaptation of microbial growth characteristics to drought

484 Adaptation of soil bacterial and fungal community characteristics to drought was

485 evaluated by assessing their growth and respiration rate responses to a subsequent

486 drying/rewetting cycle in soil samples that had been recovering for one month after

487 drought. We did two complementary tests: first, we assessed the response to a full

488 drying/rewetting cycle, to compare the ability of microbial communities to recover after

489 rewetting and secondly, we evaluated moisture dependences to test the ability of

490 microbes to withstand a lack of moisture. For the first test, soil samples were

491 completely air dried for two days and then rewetted to 60\% WHC. After rewetting,

492 microbial growth rates were measured with a high temporal resolution of approximately

$4936 \mathrm{~h}$ for a $160 \mathrm{~h}$ period (more frequent at the beginning and every $24 \mathrm{~h}$ afterwards, 12

494 time points in total). Bacterial and fungal growth rates were assessed via radioisotope

495 incorporation ${ }^{85}$. Bacterial growth rates were evaluated by ${ }^{3} \mathrm{H}$-leucine incorporation into

496 proteins ${ }^{86}$ while fungal growth rates were measured by ${ }^{14} \mathrm{C}$-acetate incorporation into

497 ergosterol ${ }^{87}$. To measure soil respiration, $1.0 \mathrm{~g}$ of soil was weighed into $20-\mathrm{ml}$ glass 
498 vials, which were purged with pressurised air, sealed with crimp caps and incubated for

$4996 \mathrm{~h}$ in the dark at $17^{\circ} \mathrm{C} \cdot \mathrm{CO}_{2}$ production was measured using a gas chromatograph

500 equipped with a methaniser and an FID detector. To evaluate the moisture dependence

501 of microbial processes, microbial growth and respiration rates were measured during the

502 drying down of the soils. Then, $\mathrm{IC}_{10}$ (i.e. the moisture level at which growth and

503 respiration rates were reduced by 10\%) was determined, which allowed comparison of

504 the drought tolerance of the different microbial processes ${ }^{22}$.

\section{Statistical analyses}

506 All statistical analyses were done in $\mathrm{R} \mathrm{v4.0}{ }^{88}$. To evaluate microbial community 507 structure, we investigated alpha diversity, community structure with ordination 508 analyses, proportion of different taxa and functional guilds (only for fungi) and we 509 performed indicator species analysis. Due to the issues associated with using rarefied or 510 relative abundance data for diversity tests and differential abundance analyses ${ }^{89}$, 511 different approaches or data transformations were applied for each analysis.

512 Alpha diversity was calculated estimating the unobserved diversity ${ }^{90}$. Richness was 513 estimated with "breakaway" package ${ }^{91}$ and Shannon index with "DivNet" package". 514 Community structure was explored with a variance stabilization transformation (VST) 515 of data, using "DeSeq2" package ${ }^{93}$. PERMANOVA analyses using Euclidean distance 516 of transformed data were performed to evaluate differences among drought treatments, 517 with soil as random factor, using adonis function in "vegan" package ${ }^{73}$. To better 518 visualise the effects of the drought treatments, a correction to eliminate the soil effect 519 was performed with removeBatchEffect function in "limma" package ${ }^{94}$. A PCA analysis 520 was then performed in the corrected database using "vegan" ${ }^{73}$. To predict functional 521 guilds and trophic modes from the fungal taxonomic data we used FUNGuild ${ }^{95}$. Only 
522 those assignments considered highly probable or probable were used, while possible

523 assignments were discarded. Assignments with multiple and contradictory guilds to the

524 same taxa were also discarded. In average, $29.1 \%$ of the taxa (774 ASVs) were assigned

525 and used in this analysis. Of those, 82 were assigned to order level, 158 to family level

526 and 534 to genus level. For relative abundance graphs, only taxa (phylum, order or

527 family) with relative abundances $>1 \%$ across all samples were plotted.

528 Indicator species analysis was performed using multipatt function in the

529 "indicspecies" package ${ }^{96}$ to identify bacterial and fungal taxa associated with drought

530 and control treatments. We tested for indicator taxa depending on the intensity of

531 drought, comparing the control treatment with the extreme drought and some specific

532 combinations (control+mild, control+mild+intermediate, and intermediate+extreme

533 drought). Prior to analysis, ASVs were agglomerated at genus level using tax_glom in

534 "phyloseq" package ${ }^{97}$, and libraries were normalised using cumulative sum scaling

$535(\mathrm{CSS})^{98}$, using phyloseq_transform_css function in "metagMisc" package ${ }^{99}$. CSS-

536 normalised abundance heatmaps were produced using plot_heatmap function in

537 "phyloseq" package ${ }^{97}$.

538 Resistance and resilience of soil functions were evaluated with a linear regression 539 analysis between the value of the variable under drought and time after drought (in

540 weeks). We used relative data in percentage (i.e., value drought pot/value control pot $\times$

541 100), and we performed individual analyses for each of the nine drought intensity and

542 drought frequency combinations. The value of the intercept was used as a resistance

543 index (RS), as it represents the relative difference of the drought treatment with the

544 control just after drought. RS can be directly interpreted as the \% change compared to

545 the control treatment. Additionally, we used the value of the slope as a resilience index

546 (RL). This value was adjusted depending on the direction of change after drought with 
547 the formula: if intercept $<100$, then $\mathrm{RL}=$ slope; if intercept $>100$, then $\mathrm{RL}=-$ slope.

548 Thus, a positive RL indicates a recovery of the system; variables in drought pots are

549 getting more similar to those in control pots. On the other hand, RL $=0$ reflects no

550 change (no resilience), with drought pots showing the same difference with the control

551 ones that what it was at the end of the drought. Moreover, a negative RL can be

552 interpreted as delayed response to drought or a continuous negative effect even when

553 the perturbation has finished, as negative RL mean a bigger difference with the control

554 over time than what it was at the end of the drought. RL values can be directly

555 interpreted as percentage recovery/change per week.

556 Soil functional data (soil extracellular enzymes and nutrient pools) were used in a 557 non-metric multidimensional scaling (NMDS) ordination analysis, performed with the 558 function metaMDS in "vegan",73, using relative data (value/average of the control at 559 each sampling date). Multifunctionality index ${ }^{100}$ was calculated with all the soil 560 enzymatic activities, which represent the organic matter decomposition capacity of 561 soils. Data were standardised by $\mathrm{z}$ transformation separately for each sampling time, 562 which removed overall differences between harvest time points ${ }^{101}$. Subsequently, the 563 average of all standardised values was used as the multifunctionality index.

564 The effects of drought intensity and frequency in all variables were analysed by 565 linear mixed effect models (LME) with drought intensity and frequency as fixed factors 566 and soil as random factor, with lme function in "nmle" package ${ }^{102}$. To obtain a balanced 567 design, control pots were removed from the analysis. Normality of the residuals and 568 homoscedasticity were confirmed with Anderson-Darling test and Levene test, 569 respectively. If needed, natural logarithmic or square root transformations were applied. 570 If the assumptions were still not met, Kruskal-Wallis test was performed instead. $P$ 
571 values after multiple comparisons (for bacterial and fungal taxa) were adjusted with the

572 Benjamini-Hochberg adjustment ${ }^{103,104}$ using p.adjust function. 


\section{REFERENCES}

575 1. Jansson, J. K. \& Hofmockel, K. S. Soil microbiomes and climate change. Nat.

$576 \quad$ Rev. Microbiol. 18, 35-46 (2020).

577 2. IPCC. Climate Change 2021: The Physical Science Basis. Working Group I

578 contribution to the Sixth Assessment Report of the Intergovernmental Panel on

$579 \quad$ Climate Change. (2021).

580 3. Naylor, D. \& Coleman-Derr, D. Drought stress and root-associated bacterial

581 communities. Front. Plant Sci. 8, 1-16 (2018).

582 4. Schimel, J. P. Life in dry soils: effects of drought on soil microbial communities

583 and processes. Annu. Rev. Ecol. Evol. Syst. 49, 409-432 (2018).

584 5. Evans, S. E. \& Wallenstein, M. D. Climate change alters ecological strategies of $585 \quad$ soil bacteria. Ecol. Lett. 17, 155-164 (2014).

586 6. Kaisermann, A., de Vries, F. T., Griffiths, R. I. \& Bardgett, R. D. Legacy effects 587 of drought on plant-soil feedbacks and plant-plant interactions. New Phytol. 215, $588 \quad 1413-1424(2017)$.

589 7. Bardgett, R. D. \& Caruso, T. Soil microbial community responses to climate 590 extremes: resistance, resilience and transitions to alternative states. Philos. Trans.

$591 \quad$ R. Soc. B Biol. Sci. 375, 20190112 (2020).

592 8. Scheffer, M., Carpenter, S., Foley, J. A., Folke, C. \& Walker, B. Catastrophic $593 \quad$ shifts in ecosystems. Nature 413, 591-596 (2001).

594 9. Wernberg, T. et al. Climate-driven shift of a temperate marine ecosystem.

$595 \quad$ Science (80-. ). 353, 169-172 (2016). 
596 10. Yodzis, P. The stability of real ecosystems. Nature 289, 674-676 (1981).

597 11. Bush, T. et al. Oxic-anoxic regime shifts mediated by feedbacks between

598 biogeochemical processes and microbial community dynamics. Nat. Commun. 8, $599 \quad 789(2017)$.

600

12. Fletcher, M.-S., Wood, S. W. \& Haberle, S. G. A fire driven shift from forest to non-forest: evidence for alternative stable states? Ecology 95, 2504-2513 (2014).

13. Abella, S. R., Gentilcore, D. M. \& Chiquoine, L. P. Resilience and alternative stable states after desert wildfires. Ecol. Monogr. 91, e01432 (2021).

14. Lozupone, C. A., Stombaugh, J. I., Gordon, J. I., Jansson, J. K. \& Knight, R. Diversity, stability and resilience of the human gut microbiota. Nature 489, 220230 (2012).

15. Hartman, A. L. et al. Human gut microbiome adopts an alternative state following small bowel transplantation. Proc. Natl. Acad. Sci. U. S. A. 106,

16. Bardgett, R. D. \& Van Der Putten, W. H. Belowground biodiversity and ecosystem functioning. Nature 515, 505-511 (2014).

17. Bender, E. A. ., Case, T. J. . \& Gilpin, M. E. . Perturbation experiments in community ecology: theory and practice. Ecology 65, 1-13 (1984).

18. Barnard, R. L., Osborne, C. A. \& Firestone, M. K. Responses of soil bacterial and fungal communities to extreme desiccation and rewetting. ISME J. 7, 2229$2241(2013)$ 
legacy affects microbial community trait distributions related to moisture along a savannah grassland precipitation gradient. J. Ecol. 1-16 (2020) doi:10.1111/1365-2745.13550.

20. de Vries, F. T. et al. Soil bacterial networks are less stable under drought than fungal networks. Nat. Commun. 9, 3033 (2018).

21. Bouskill, N. J. et al. Pre-exposure to drought increases the resistance of tropical forest soil bacterial communities to extended drought. ISME J. 7, 384-394

26. Petraitis, P. S. \& Dudgeon, S. R. Detection of alternative stable states in marine

24. Jassey, V. E. J. et al. Tipping point in plant-fungal interactions under severe drought causes abrupt rise in peatland ecosystem respiration. Glob. Chang. Biol. 24, 972-986 (2018).

25. Todman, L. C. et al. Evidence for functional state transitions in intensivelymanaged soil ecosystems. Sci. Rep. 8, 11522 (2018). and current drought on the composition and diversity of soil microbial 
communities. Soil Biol. Biochem. 131, 28-39 (2019).

641
28. Lennon, J. T., Aanderud, Z. T., Lehmkuhl, B. K. \& Schoolmaster, D. R. Mapping the niche space of soil microorganisms using taxonomy and traits. Ecology 93, 1867-1879 (2012).

29. Pérez Castro, S., Cleland, E. E., Wagner, R., Sawad, R. Al \& Lipson, D. A. Soil microbial responses to drought and exotic plants shift carbon metabolism. ISME J. 13, 1776-1787 (2019).

30. Curiel Yuste, J. et al. Strong functional stability of soil microbial communities under semiarid Mediterranean conditions and subjected to long-term shifts in baseline precipitation. Soil Biol. Biochem. 69, 223-233 (2014).

31. Jang, S. W. et al. Re-Analysis of $16 \mathrm{~S}$ amplicon sequencing data reveals soil microbial population shifts in rice fields under drought condition. Rice 13, 44 (2020).

32. Brewer, T. E., Handley, K. M., Carini, P., Gilbert, J. A. \& Fierer, N. Genome reduction in an abundant and ubiquitous soil bacterium 'Candidatus Udaeobacter copiosus'. Nat. Microbiol. 2, 16198 (2016).

33. Thijs, S. et al. Potential for plant growth promotion by a consortium of stresstolerant 2,4-dinitrotoluene-degrading bacteria: isolation and characterization of a military soil. Microb. Biotechnol. 7, 294-306 (2014).

34. Ofek, M., Hadar, Y. \& Minz, D. Ecology of root colonizing Massilia (Oxalobacteraceae). PLoS One 7, e40117 (2012).

35. Viitamäki, S. The activity and functions of soil microbial communities across a 
662

climate gradient in Finnish subarctic. (University of Helsinki, 2019).

36. Moreno, J. L., Torres, I. F., García, C., López-Mondéjar, R. \& Bastida, F. Land use shapes the resistance of the soil microbial community and the $\mathrm{C}$ cycling response to drought in a semi-arid area. Sci. Total Environ. 648, 1018-1030 (2019).

37. Bapiri, A., Bååth, E. \& Rousk, J. Drying-rewetting cycles affect fungal and bacterial growth differently in an arable soil. Microb. Ecol. 60, 419-428 (2010).

38. Fierer, N. \& Jackson, R. B. The diversity and biogeography of soil bacterial communities. Proc. Natl. Acad. Sci. 103, 626-631 (2006).

39. Rousk, J. et al. Soil bacterial and fungal communities across a $\mathrm{pH}$ gradient in an arable soil. ISME J. 4, 1340-1351 (2010).

40. Tedersoo, L. et al. Global diversity and geography of soil fungi. Science (80-. ). 346, 1256688 (2014).

41. Xiao, W., Chen, X., Jing, X. \& Zhu, B. A meta-analysis of soil extracellular enzyme activities in response to global change. Soil Biol. Biochem. 123, 21-32 (2018).

42. Burns, R. G. et al. Soil enzymes in a changing environment: Current knowledge and future directions. Soil Biol. Biochem. 58, 216-234 (2013).

43. Ochoa-Hueso, R. et al. Drought consistently alters the composition of soil fungal and bacterial communities in grasslands from two continents. Glob. Chang. Biol. (2018) doi:10.1111/gcb.14113.

44. Acosta-Martinez, V., Moore-Kucera, J., Cotton, J., Gardner, T. \& Wester, D. Soil 
enzyme activities during the 2011 Texas record drought/heat wave and implications to biogeochemical cycling and organic matter dynamics. Appl. Soil Ecol. 75, 43-51 (2014).

45. Williams, M. A. \& Xia, K. Characterization of the water soluble soil organic pool following the rewetting of dry soil in a drought-prone tallgrass prairie. Soil Biol. Biochem. 41, 21-28 (2009).

46. Austin, A. T. et al. Water pulses and biogeochemical cycles in arid and semiarid ecosystems. Oecologia 141, 221-235 (2004).

47. Fierer, N. \& Schimel, J. P. Effects of drying-rewetting frequency on soil carbon and nitrogen transformations. Soil Biol. Biochem. 34, 777-787 (2002).

48. Hueso, S., García, C. \& Hernández, T. Severe drought conditions modify the microbial community structure, size and activity in amended and unamended soils. Soil Biol. Biochem. 50, 167-173 (2012).

49. Fuchslueger, L., Bahn, M., Fritz, K., Hasibeder, R. \& Richter, A. Experimental drought reduces the transfer of recently fixed plant carbon to soil microbes and alters the bacterial community composition in a mountain meadow. New Phytol. 201, 916-927 (2014).

50. Dijkstra, F. A., He, M., Johansen, M. P., Harrison, J. J. \& Keitel, C. Plant and microbial uptake of nitrogen and phosphorus affected by drought using ${ }^{15} \mathrm{~N}$ and ${ }^{32}$ P tracers. Soil Biol. Biochem. 82, 135-142 (2015).

51. Rousk, J., Smith, A. R. \& Jones, D. L. Investigating the long-term legacy of drought and warming on the soil microbial community across five European shrubland ecosystems. Glob. Chang. Biol. 19, 3872-3884 (2013). 
707 52. Hicks, L. C., Ang, R., Leizeaga, A. \& Rousk, J. Bacteria constrain the fungal

708 growth response to drying-rewetting. Soil Biol. Biochem. 134, 108-112 (2019).

709 53. de Vries, F. T. \& Shade, A. Controls on soil microbial community stability under $710 \quad$ climate change. Front. Microbiol. 4, 265 (2013).

711

54. Fukami, T. Historical contingency in community assembly: integrating niches, species pools, and priority effects. Annu. Rev. Ecol. Evol. Syst. 46, 1-23 (2015).

55. Kreyling, J. et al. To replicate, or not to replicate - that is the question: how to tackle nonlinear responses in ecological experiments. Ecol. Lett. 21, 1629-1638 (2018).

56. Meisner, A., Leizeaga, A., Rousk, J. \& Bååth, E. Partial drying accelerates bacterial growth recovery to rewetting. Soil Biol. Biochem. 112, 269-276 (2017).

57. Shade, A. et al. Fundamentals of microbial community resistance and resilience. Front. Microbiol. 3, 417 (2012).

58. Williams, A. \& de Vries, F. T. Plant root exudation under drought: implications for ecosystem functioning. New Phytol. 225, 1899-1905 (2020).

59. Dorigo, W. et al. ESA CCI Soil Moisture for improved Earth system understanding: State-of-the art and future directions. Remote Sens. Environ. 203, $185-215$ (2017).

60. Gruber, A., Scanlon, T., Van Der Schalie, R., Wagner, W. \& Dorigo, W. Evolution of the ESA CCI Soil Moisture climate data records and their underlying merging methodology. Earth Syst. Sci. Data 11, 717-739 (2019). 
in R. J. Stat. Softw. 72, 1-39 (2016).

730

62. Ahmadi, K. et al. Effects of rhizosphere wettability on microbial biomass, enzyme activities and localization. Rhizosphere 7, 35-42 (2018).

63. Taylor, D. et al. Accurate estimation of fungal diversity and abundance through improved lineage-specific primers optimized for Illumina amplicon sequencing. Appl. Environ. Microbiol. 82, 7217-7226 (2016).

64. Herlemann, D. P. R. et al. Transitions in bacterial communities along the 2000 km salinity gradient of the Baltic Sea. ISME J. 5, 1571-1579 (2011).

65. Bakker, M. G. A fungal mock community control for amplicon sequencing experiments. Mol. Ecol. Resour. 18, 541-556 (2018).

66. Andrews, S. FastQC: A quality control tool for high throughput sequence data. http://www.bioinformatics.babraham.ac.uk/projects/. (2010).

67. Martin, M. Cutadapt removes adapter sequences from high-throughput sequencing reads. EMBnet.journal 17, 10-12 (2011).

68. Boyer, F. et al. OBITOOLS: A UNIX-inspired software package for DNA metabarcoding. Mol. Ecol. Resour. 16, 176-182 (2016).

69. Callahan, B. J. et al. DADA2: High-resolution sample inference from Illumina amplicon data. Nat. Methods 13, 581-583 (2016).

70. Wright, E. S. Using DECIPHER v2.0 to analyze big biological sequence data in R. $R$ J. 8, 352-359 (2016).

71. Wangensteen, O. S., Palacín, C., Guardiola, M. \& Turon, X. DNA metabarcoding of littoral hard-bottom communities: high diversity and database gaps revealed 
$751 \quad$ by two molecular markers. PeerJ 6, e4705 (2018).

752 72. Frøslev, T. G. et al. Algorithm for post-clustering curation of DNA amplicon

753 data yields reliable biodiversity estimates. Nat. Commun. 8, 1188 (2017).

754 73. Oksanen, J. et al. vegan: community ecology package. R package version 2.5 .

$755 \quad(2020)$

$75674 . \quad$ Jackson, C. R., Tyler, H. L. \& Millar, J. J. Determination of microbial

757 extracellular enzyme activity in waters, soils, and sediments using high

758 throughput microplate assays. J. Vis. Exp. 80, 1-9 (2013).

759 75. Cordero, I., Snell, H. \& Bardgett, R. D. High throughput method for measuring

$760 \quad$ urease activity in soil. Soil Biol. Biochem. 134, 72-77 (2019).

761 76. Sinsabaugh, R. L. \& Linkins, A. E. Exoenzyme activity associated with lotic

762 epilithon. Freshw. Biol. 20, 249-261 (1988).

77. DeForest, J. L. The influence of time, storage temperature, and substrate age on potential soil enzyme activity in acidic forest soils using MUB-linked substrates and 1-DOPA. Soil Biol. Biochem. 41, 1180-1186 (2009).

79. Kuo, S. Phosphorus. in Methods of soil analysis, Part 3. Chemical methods (eds. 
measure microbial biomass nitrogen in soil. Soil Biol. Biochem. 17, 837-842 (1985).

775 81. Vance, E. D., Brookes, P. C. \& Jenkinson, D. S. An extraction method for measuring soil microbial biomass C. Soil Biol. Biochem. 19, 703-707 (1987).

82. Sparling, G. P., Feltham, C. W., Reynolds, J., West, A. W. \& Singleton, P.

85. Rousk, J. \& Bååth, E. Growth of saprotrophic fungi and bacteria in soil. FEMS

84. Brookes, P. C., Powlson, D. S. \& Jenkinson, D. S. Measurement of microbial biomass phosphorus in soil. Soil Biol. Biochem. 14, 319-329 (1982).

86. Bååth, E. Measurement of protein synthesis by soil bacterial assemblages with the leucine incorporation technique. Biol. Fertil. Soils 17, 147-153 (1994).

87. Bååth, E. Estimation of fungal growth rates in soil using ${ }^{14} \mathrm{C}$-acetate incorporation into ergosterol. Soil Biol. Biochem. 33, 2011-2018 (2001).

88. R Core Team, _. $R$ : a language and environment for statistical computing. ( $\mathrm{R}$ Foundation for Statistical Computing, 2020).

794 89. McMurdie, P. J. \& Holmes, S. Waste not, want not: why rarefying microbiome 
data is inadmissible. PLoS Comput. Biol. 10, e1003531 (2014).

796

797

798

799

800

801

802

803

804

805

806

807

808

809

810

811

812

813

814

815

816

90. Willis, A. D. Rarefaction, alpha diversity, and statistics. Front. Microbiol. 10, 2407 (2019).

91. Willis, A. et al. breakaway: Species Richness Estimation and Modeling. R package version 4.7.3. (2020).

92. Willis, A. D. \& Martin, B. D. Estimating diversity in networked ecological communities. Biostatistics (2020).

93. Love, M. I., Huber, W. \& Anders, S. Moderated estimation of fold change and dispersion for RNA-seq data with DESeq2. Genome Biol. 15, 1-21 (2014).

94. Ritchie, M. E. et al. limma powers differential expression analyses for RNAsequencing and microarray studies. Nucleic Acids Res. 43, e47 (2015).

95. Nguyen, N. H. et al. FUNGuild: An open annotation tool for parsing fungal community datasets by ecological guild. Fungal Ecol. 20, 241-248 (2016).

96. De Cáceres, M. \& Legendre, P. Associations between species and groups of sites: indices and statistical inference. Ecology 90, 3566-3574 (2009).

97. Mcmurdie, P. J. \& Holmes, S. phyloseq: an R package for reproducible interactive analysis and graphics of microbiome census data. PLoS One $\mathbf{8}$, e61217 (2013).

98. Paulson, J. N., Colin Stine, O., Corrada Bravo, H. \& Pop, M. Differential abundance analysis for microbial marker-gene surveys. Nat. Methods 10, 12001202 (2013).

99. Mikryukov, V. metagMisc: Miscellaneous functions for metagenomic analysis. 
(2020).

818

819

820

821

822

823

824

825

826

827

828

829

830

831

832

833

834

100. Maestre, F. T. et al. Plant species richness and ecosystem multifunctionality in global drylands. Science (80-. ). 335, 214-218 (2012).

101. Wagg, C., Bender, S. F., Widmer, F. \& Van Der Heijden, M. G. A. Soil biodiversity and soil community composition determine ecosystem multifunctionality. Proc. Natl. Acad. Sci. U. S. A. 111, 5266-5270 (2014).

102. Pinheiro, J., Bates, D., DebRoy, S., Sarkar, D. \& Team, R. C. nlme: Linear and Nonlinear Mixed Effects Models. R package version 3.1-149. (2020).

103. Benjamini, Y. \& Hochberg, Y. Controlling the false discovery rate: a practical and powerful approach to multiple testing. J. R. Stat. Soc. Ser. B 57, 289-300 (1995).

104. Jafari, M. \& Ansari-Pour, N. Why, when and how to adjust your P values? Cell J. 20, 604-607 (2019).

\section{ACKNOWLEDGMENTS}

This work was supported by a grant from the Ramon Areces Foundation and UK Biotechnology and Biological Sciences Research Council (BBSRC) Discovery Fellowship (BB/S010661/1) awarded to IC, and a BBSRC grant (BB/I009000/2) awarded to RDB. The work was also supported by a grant from the Knut and Alice Wallenberg foundation (KAW 2017.0171) awarded to JR. We are grateful to members of the Soil and Ecosystems Ecology Laboratory who helped with the running of the experiment, especially Debbie Ashworth and Diego Abad Martín, and Eva Berglund at Lund University. We also thank Lokeshwaran Manoharan, Marina Semchenko, Océane Nicolitch, Hayley Craig, Arthur Broadbent and Chris Sweeney for help with data 
840 analyses, and Dr. Matthew Bakker for proving the fungal mock community used for

841 ITS2 sequencing.

\section{AUTHOR CONTRIBUTIONS}

843 IC and RDB conceived the study and designed the experiment, with inputs from JR. 844 IC performed nutrient analyses, enzyme assays, and microbial sequencing work. AL 845 and LH performed microbial growth rates measurements. IC analysed the data and 846 wrote the manuscript, with significant contributions from all authors.

\section{COMPETING INTERESTS}

848 We declare no competing interests. 


\section{FIGURE CAPTIONS}

850

Fig. 1 | Effects of drought on soil microbial community structure. a-d, Alpha diversity 6 months after drought (mean \pm error of estimated values). e-f, Community structure. The first two axes explained $17.3 \%$ (bacteria) and $5.4 \%$ (fungi) of the variance. g, Percentage variance explained in PERMANOVA analyses including all the treatments (global) or just one plus the control. $\mathbf{i}-\mathbf{j}$, Relative abundance of microbial families. Data=mean $(n=4) . s g=$ subgroup. Significance of drought intensity (I), frequency $(\mathrm{F})$ and time point $(\mathrm{T})$ is shown $(\mathbf{a}-\mathbf{g})$ : $* \mathrm{p}<0.05, * * \mathrm{p}<0.01, * * * \mathrm{p}<0.001$, or significance of drought treatment for each sampling time (i-j): ${ }^{-} p>0.05,{ }^{*} p<0.05$.

Fig. 2 Effects of drought on soil function. a,b, Resistance and resilience indexes. Asterisks indicate significant change (value $\neq 0, \mathrm{p}<0.05)$. c,d, Functional structure of soils. Mean \pm error $(n=4)$. Significance of PERMANOVA analysis evaluating the effects of drought intensity (I) and frequency (F) is shown: $* p<0.05$, **p $<0.01$, $* * * \mathrm{p}<0.001$. Differences in data dispersion (dd) among groups is also shown $\left({ }^{\mathrm{ns}}\right.$ : nonsignificant). GLC: $\beta$-glucosidase, CBH: cellobiohydrolase, XYL: xylosidase, NAG: $N$ acetylglocasiminidase, PHO: acid phosphatase, POX: phenoloxidase, PER: peroxidase, URE: urease, DOC: dissolved organic carbon, DON: dissolved organic nitrogen, TOP: total organic phosphorus, $\mathrm{C}_{\text {mic }}$ : microbial carbon, $\mathrm{N}_{\text {mic }}$ : microbial nitrogen, $\mathrm{P}_{\text {mic }}$ : microbial phosphorus.

\section{Fig. 3 | Adaptation of microbial growth characteristics to drought. Growth} responses to a further drying/rewetting cycle of soils with different drought history, one month after drought. Significance of LME evaluating the effects of drought intensity (I) and frequency (F) is shown: $* \mathrm{p}<0.05, * * \mathrm{p}<0.01, * * * \mathrm{p}<0.001$. 


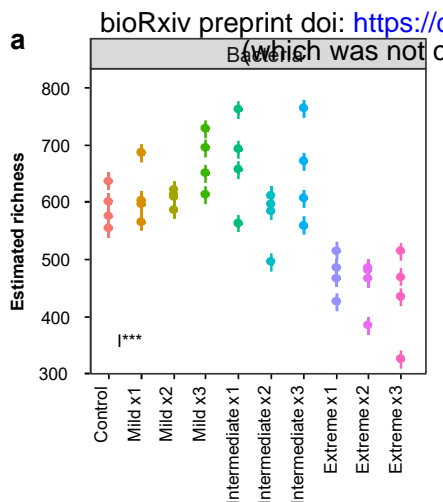

e

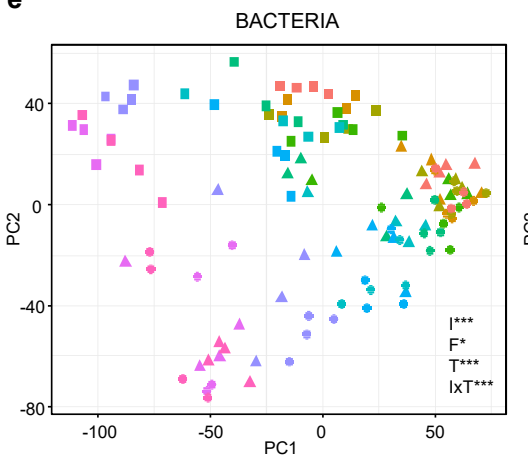

h

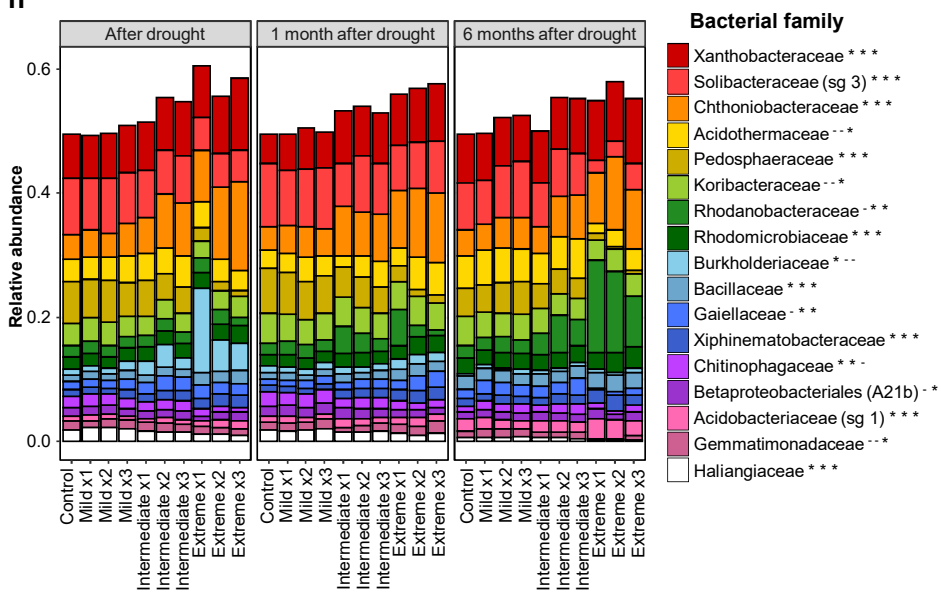

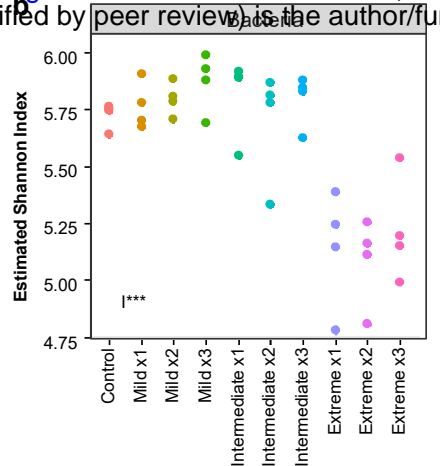

,

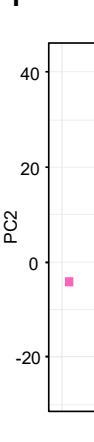

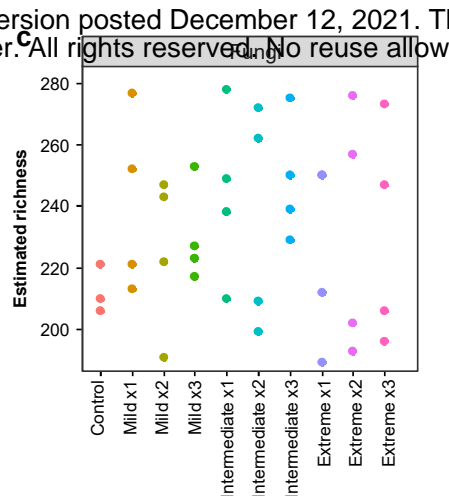
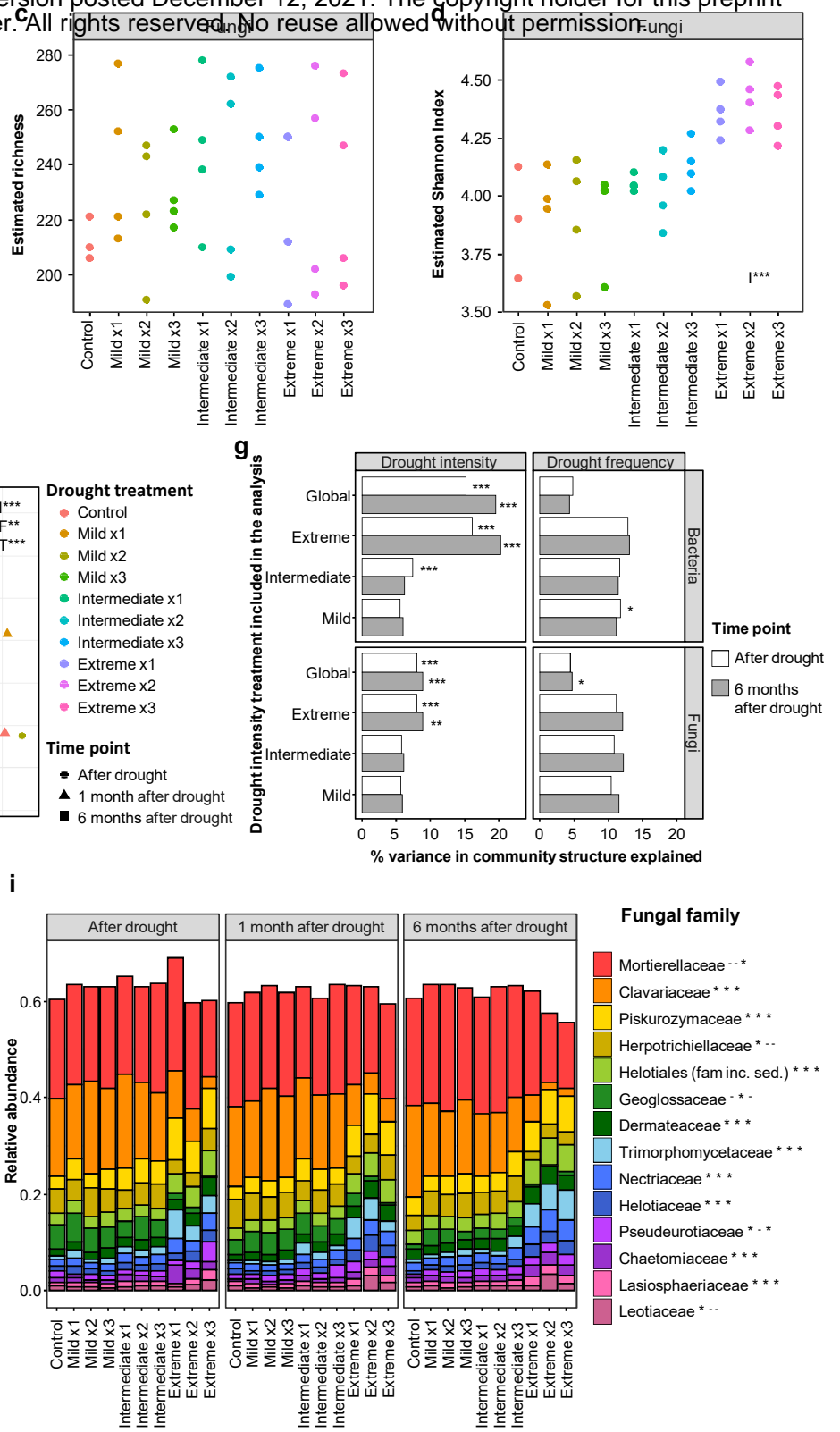

Fig. 1 | Effects of drought on soil microbial community structure. a-d, Alpha diversity 6 months after drought (mean \pm error of estimated values). e-f, Community structure. The first two axes explained $17.3 \%$ (bacteria) and $5.4 \%$ (fungi) of the variance. g, Percentage variance explained in PERMANOVA analyses including all the treatments (global) or just one plus the control. $\mathbf{i}-\mathbf{j}$, Relative abundance of microbial families. Data=mean $(n=4) . s g=$ subgroup. Significance of drought intensity $(I)$, frequency $(F)$ and time point $(T)$ is shown $(a-g):{ }^{*} p<0.05$, ${ }^{* *} p<0.01$, ${ }^{* * *} p<0.001$, or significance of drought treatment for each sampling time $(\mathbf{i}-\mathbf{j}):-p>0.05,{ }^{*} p<0.05$. 
bioRxiv preprint doi: https://doi.org/10.1101/2021.12.10.472086; this version posted December 12, 2021. The copyright holder for this preprint
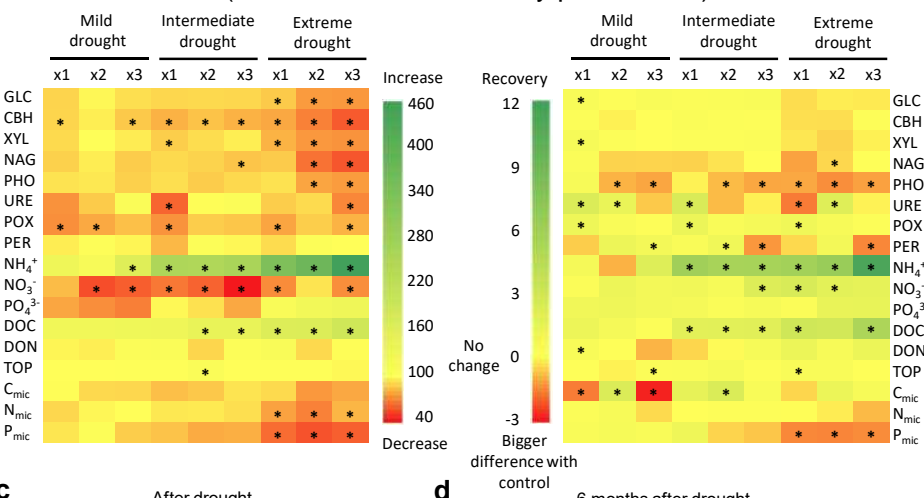

d control 6 months after drought
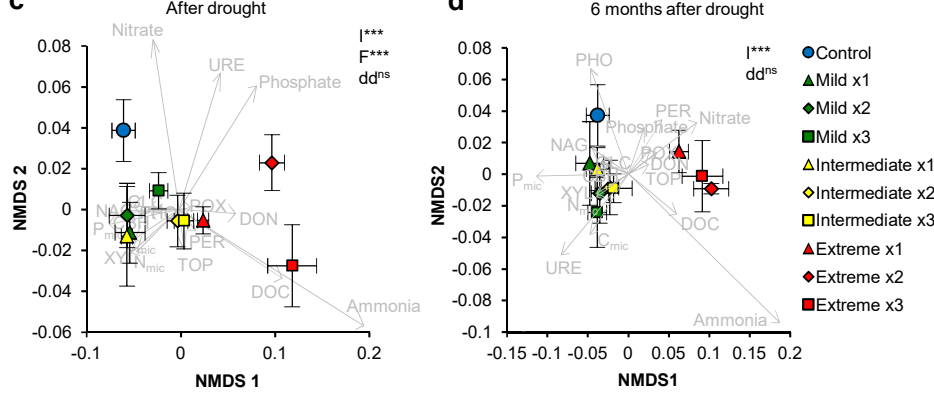

Fig. 2 Effects of drought on soil function. a,b, Resistance and resilience indexes. Asterisks indicate significant change (value $\neq 0$, $p<0.05)$. c,d, Functional structure of soils. Mean \pm error $(n=4)$. Significance of PERMANOVA analysis evaluating the effects of drought intensity (I) and frequency $(F)$ is shown: ${ }^{*} p<0.05$, ${ }^{* *} p<0.01,{ }^{* * *} p<0.001$. Differences in data dispersion (dd) among groups is also shown (ns: nonsignificant). GLC: $\beta$-glucosidase, $\quad \mathrm{CBH}$ : cellobiohydrolase, $\mathrm{XYL}$ : xylosidase, NAG: $N$-acetylglocasiminidase, $\mathrm{PHO}$ : acid phosphatase, POX: phenoloxidase, PER: peroxidase, URE: urease, DOC: dissolved organic carbon, DON: dissolved organic nitrogen, TOP: total organic phosphorus, $\mathrm{C}_{\text {mic }}$ : microbial carbon, $\mathrm{N}_{\text {mic }}$ : microbial nitrogen, $\mathrm{P}_{\text {mic }}$ : microbial phosphorus. 
bioRxiv preprint doi: https://dpi.org/10.1101/2021.12.10.472086; this version posted December 12, 2021. The copyright holder for this preprint

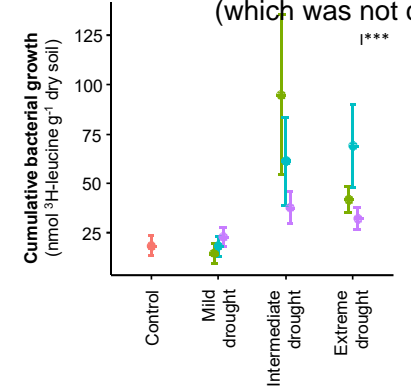

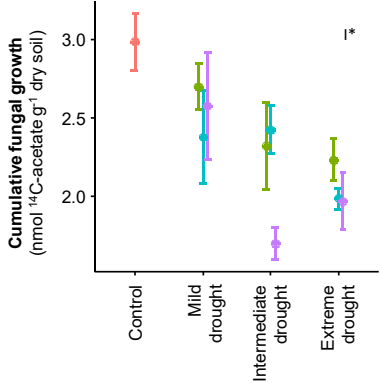

d

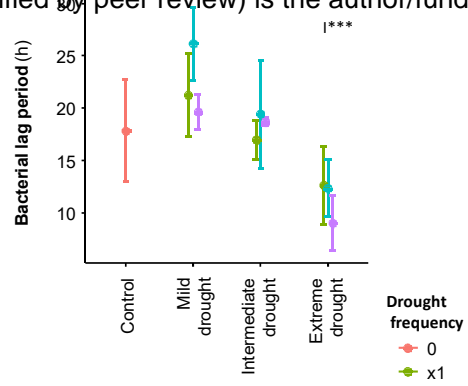

$\begin{aligned}-0 & -0 \\ & -x 1\end{aligned}$

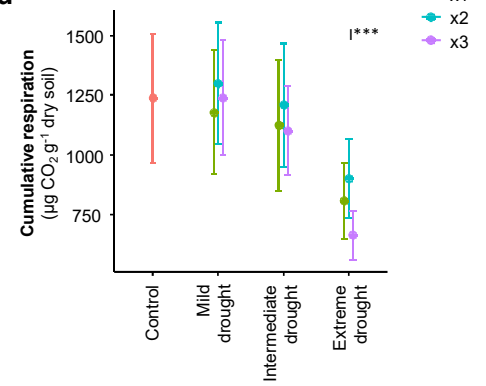

Fig. 3 | Adaptation to drought of microbial community traits.

Growth responses to a further drying/rewetting cycle of soils with different drought history, one month after drought. Significance of LME evaluating the effects of drought intensity (I) and frequency $(F)$ is shown: ${ }^{*} p<0.05,{ }^{* *} p<0.01,{ }^{* * *} p<0.001$. 